DOI: https://doi.org/10.24867/14AM04Kuzovic

\title{
NUMERIČKA SIMULACIJA PROCESA SABIJANJA U USLOVIMA RAVANSKE DEFORMACIJE SA EKSPERIMENTALNOM PROVEROM
}

\section{THE NUMERICAL SIMULATION OF PLANE STRAIN UPSETTING PROCES CONDITIONS WITH EXPERIMENTAL VERIFICATION}

Milomir Kuzović, Marko Vilotić, Jovan Dorić, Fakultet tehničkih nauka, Novi Sad

\section{Oblast - MAŠINSTVO}

Kratak sadržaj - U ovom radu izvršen je set numeričkih simulacija procesa ravanskog sabijanja sa ciljem prikupljanja informacija o ponašanju čelika DIN - Ck45 u uslovima ravanske deformacije. Prizmatični uzorak se deformiše u alatu koji mu sprečava bočno proširenje. Proces je izveden prvo pomoću numeričkih simulacija, nakon čega je izvršena eksperimentalna provera na hidrauličnoj presi.
\end{abstract}

Ključne reči: Ravansko sabijanje, plastično deformisanje, numerička simulacija

\begin{abstract}
In this paper, a set of plane strain process numerical simulations has been carried out to obtain information about the behavior of steel DIN - Ck45 in plane strain conditions. A prismatic workpiece is being deformed in the die that prevents lateral expansion. At first, the process is conducted by numerical simulations, followed by experimental verification on a hydraulic press.
\end{abstract}

Keywords: Plain strain compression, metal forming, numerical simulation

\section{UVOD}

Razvoj tehnologija plastičnog deformisanja (TPD), zajedno sa naglim napretkom u razvoju računarskih simulacija proizvodnih procesa zasnovanih na numeričkim metodama poslednjih nekoliko decenija, omogućio je pojavu novih proizvoda i polufabrikata koji su od svojih prethodnika superiorniji po mnogim parametrima $[1,2]$.

Unapređenje produktivnosti istraživača, inženjera i tehnologa koji se bave izučavanjem TPD-a kroz sposobnost simuliranja procesa numeričkim metodama imalo je za posledicu poboljšavanje gore navedenih parametara proizvoda dobijenih TPD procesima tako što im je omogućilo da jasnije vide, razumeju i prate proces proizvodnje.

Iako je napredak sposobnosti predviđanja procesa numeričkim simulacijama neosporan, mora se uzeti u obzir da postoje granični slučajevi procesa u vidu parametara simulacije, geometrije alata i pripremka, osobina materijala koji se simulira i drugi koji ne retko dovode do nedovoljno tačnih i loših rezultata.

\section{NAPOMENA:}

Ovaj rad proistekao je iz master rada čiji mentor je bio dr Marko Vilotić, docent.
Ovakvi rezultati posledica su mnogih ograničavajućih faktora koji se javljaju kod simulacija numeričkim metodama.

Zbog ovih ograničavajućih faktora neophodno je izvršiti eksperimentalna ispitivanja realnog procesa obrade, koja imaju za cilj proveru rezultata dobijenih metodama numeričkih simulacija. Glavni nedostatak eksperimentalnih ispitivanja u odnosu na računarske simulacije je značajno viša cena i utrošak resursa za dobijanje rezultata. Iz ovog nedostatka stvara se prirodna težnja istraživača da se obim eksperimentalnih ispitivanja svede na minimum koji daje zadovoljavajuće rezultate. Takva težnja dovela je do potrebe industrije za poboljšavanjem mogućnosti numeričkih simulacija.

\section{ZADATAK SIMULACIJE PROCESA RAVANSKOG SABIJANJA}

Zadatak ovog rada jeste prikupljanje informacija o ponašanju pripremka prizmatičnog oblika, izrađenog od čelika DIN - Ck45 pomoću numeričkih simulacija praćenih eksperimentalnom proverom rezultata. Proces deformisanja izvršen je u hladnom stanju u uslovima ravanske deformacije u alatu koji sprečava bočno proširenje obratka tokom procesa deformisanja. Softver korišćen za simulacije procesa deformisanja je SFTC Deform 11.0. Šema procesa prikazana je na slici 2.1 .
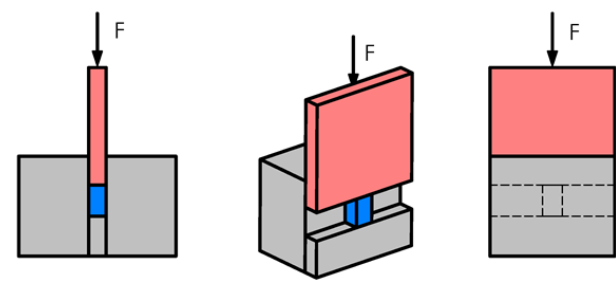

Legenda:

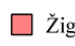

$\square$ Pripremak

$\square$ Matrica

Slika 2.1. Šema procesa sabijanja sa ograničenim bočnim širenjem

Simulacije operacije sabijanja urađene su u pet varijanti, po jednu za svaku od pet zadatih vrednosti hoda prese. Dimenzije pripremka su jednake za svih 5 varijanti simulacija procesa. Slika 2.2 prikazuje geometriju pripremaka, a tabela 2.1 sadrži njihove podatke.

Za svih pet simulacija izvršeno je praćenje parametara neophodnih za obradu rezultata simulacije. Sve simulacije imaju iste ulazne parametre izuzev hoda i broja koraka praćenja simulacije.

Potrebno je prikazati sledeće rezultate simulacija: dijagram sila-hod, tabelu koja sadrži vrednosti maksimalne sile deformisanja i tabelu koja sadrži tvrdoću uzoraka nakon procesa deformisanja. 


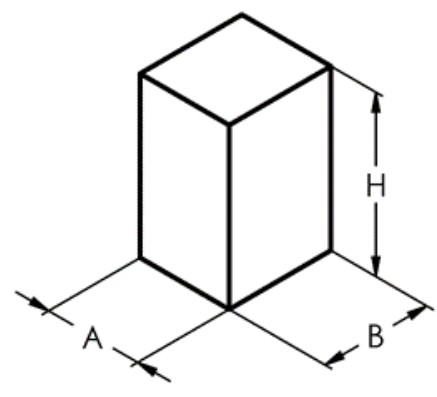

Slika 2.2. Pripremak za sabijanje u uslovima ravanske deformacije

Tabela 2.1. Podaci o pripremku

\begin{tabular}{|ll|}
\hline Materijal & \\
\hline SRPS & C 1531 \\
\hline DIN & Ck45 \\
\hline EN & C45E \\
\hline Dimenzije (mm) & \\
\hline A & 14 \\
\hline B & 16 \\
\hline H & 25 \\
\hline Tvrdoća Vickers metod & \\
\hline HV10 & 170 \\
\hline
\end{tabular}

\section{ULAZNI PARAMETRI SIMULACIJA}

Svih pet simulacija izvršeno je pomoću modula za zapreminsko deformisanje u hladnom stanju (3D - Cold Forming). Matrica - donji alat i žig - donji alat su simulirani kao kruta tela. Karakteristike pripremka definisane su iz baze podatka materijala za čelik DIN - Ck45. Mreža pripremka sastoji se iz 20000 elemenata.

Brzina kretanja gornjeg alata je $0.5 \mathrm{~mm} / \mathrm{s}$. Zadata vrednost koeficijenta trenja je 0.12 . Sve simulacije imaju iste ulazne parametre izuzev hoda i broja koraka praćenja simulacije koji su dati u tabeli 3.1.

Tabela 3.1. Plan simulacija

\begin{tabular}{|c|c|c|}
\hline \multicolumn{3}{|c|}{ Plan simulacija } \\
\hline Broj simulacije & Hod (mm) & $\begin{array}{c}\text { Broj koraka } \\
\text { praćenja }\end{array}$ \\
\hline 1. & 4 & 40 \\
\hline 2. & 8 & 80 \\
\hline 3. & 11 & 110 \\
\hline 4. & 14 & 140 \\
\hline 5. & 16 & 160 \\
\hline
\end{tabular}

\section{GEOMETRIJA PRIPREMKA I ALATA}

Geometrija matrice je modelirana kao tri tela (multi-body part), nalik realnom alatu korišćenom prilikom eksperimentalnih ispitivanja. Ovo je omogućilo da rezultat simulacije ima slične ivice kao radni komad $u$ eksperimentalnim ispitivanjima.
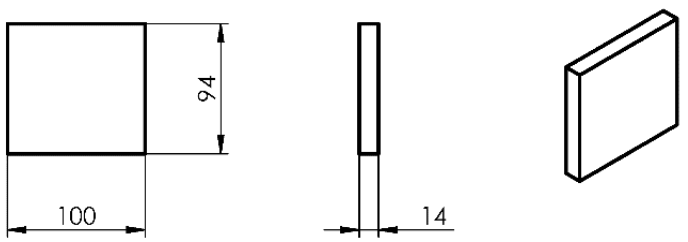

Slika 3.1. Gornji alat - Žig

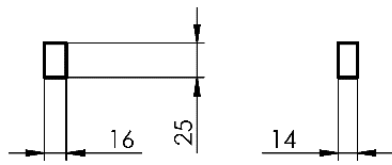

(1)

Slika 3.2. Pripremak
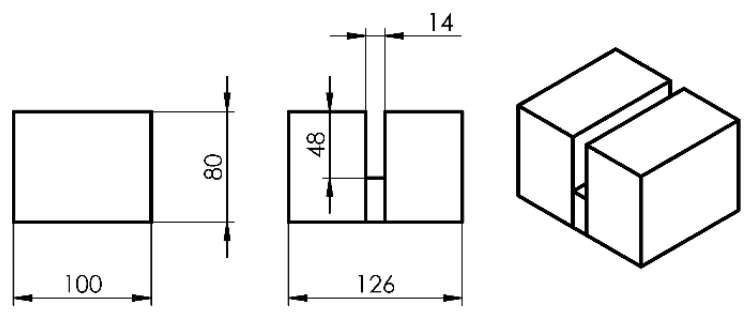

Slika 3.3. Donji alat - Matrica

\section{REZULTATI SIMULACIJA I EKSPERIMENTALNA PROVERA}

Promena geometrije uzorka tokom procesa deformisanja kroz svih pet faza prikazana je na slici 5.1. Na slici 5.2 prikazana je mreža konačnih elemenata uzorka pre deformisanja. Slika 5.3 prikazuje konačan izgled mreže konačnih elemenata uzorka nakon deformisanja.

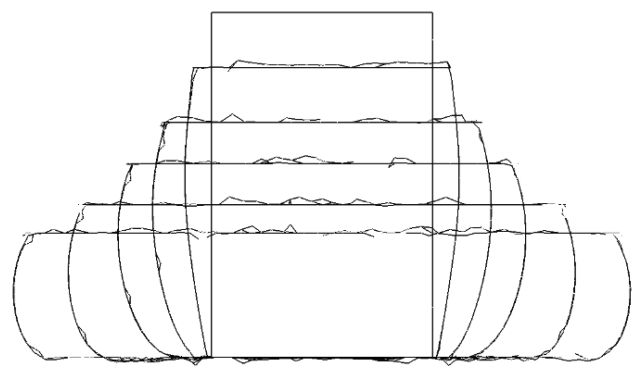

Slika 5.1. Promena geometrije tokom simulacije procesa sabijanja uslovima ravanske deformacije sa sprečenim bočnim širenjem

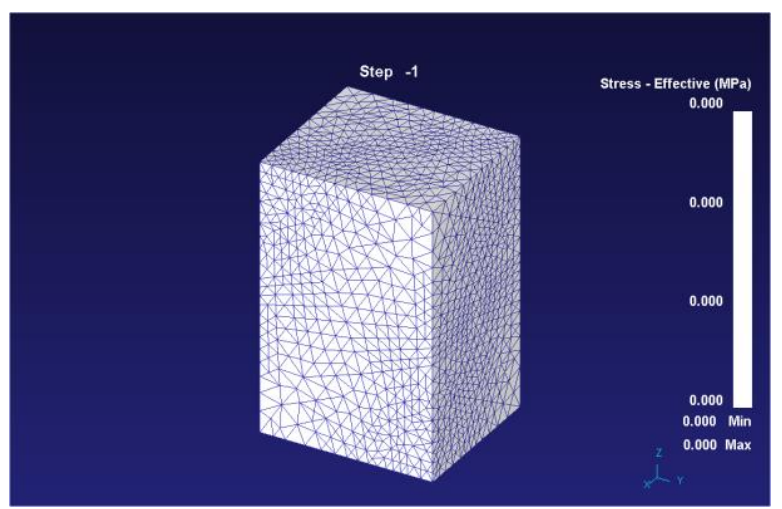

Slika 5.2. Mreža konačnih elemenata pre deformisanja 


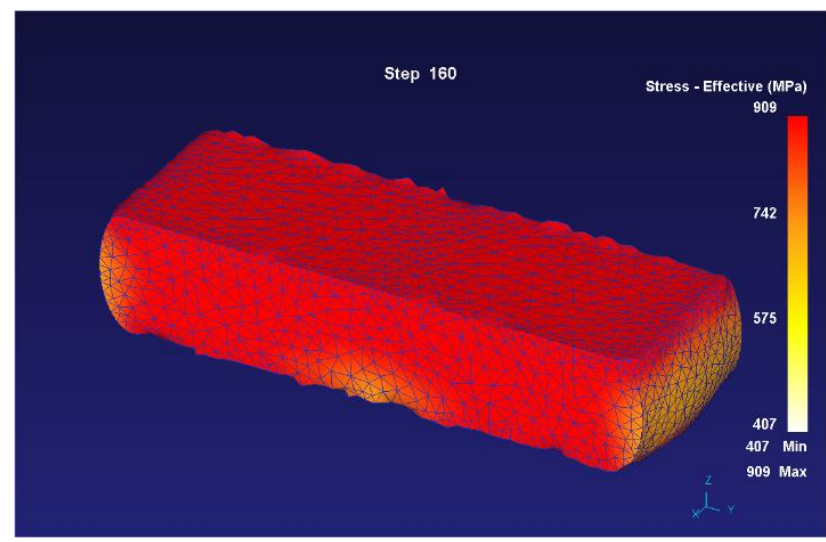

Slika 5.3. Mreža konačnih elemenata nakon maksimalne veličine hoda prese $-\mathrm{s}=16 \mathrm{~mm}$

Na slici 5.4 prikazani su uzorci nakon obrade ravanskim sabijanjem na hidrauličnoj presi.

Tabela 5.1. Maksimalna sila ostvarena tokom simulacija procesa deformisanja

\begin{tabular}{|c|c|}
\hline \multicolumn{2}{|c|}{ Maksimalna sila deformisanja simulacija } \\
\hline Broj uzorka & Sila $(\mathrm{kN})$ \\
\hline 1. & 263 \\
\hline 2. & 355 \\
\hline 3. & 441 \\
\hline 4. & 657 \\
\hline 5. & 931 \\
\hline
\end{tabular}

Tabela 5.2. Maksimalna sila ostvarena tokom eksperimentalnih ispitivanja procesa deformisanja

\begin{tabular}{|c|c|}
\hline \multicolumn{2}{|c|}{$\begin{array}{c}\text { Maksimalna sila deformisanja eksperimentalnih } \\
\text { ispitivanja }\end{array}$} \\
\hline Broj uzorka & Sila $(\mathrm{kN})$ \\
\hline 1. & 217 \\
\hline 2. & 304 \\
\hline 3. & 399 \\
\hline 4. & 618 \\
\hline 5. & 917 \\
\hline
\end{tabular}

Tabela 5.3. Tvrdoća uzoraka nakon obrade deformisanjem izmerena Vickers metodom

\begin{tabular}{|c|c|}
\hline \multicolumn{2}{|c|}{ Tvrdoća uzoraka nakon deformisanja } \\
\hline Broj uzorka & Tvrdoća HV10 \\
\hline 0. & 170 \\
\hline 1. & 236 \\
\hline 2. & 280 \\
\hline 3. & 275 \\
\hline 4. & 292 \\
\hline 5. & 289 \\
\hline
\end{tabular}

Tabela 5.4. Konačne dimenzije uzoraka nakon simulacija
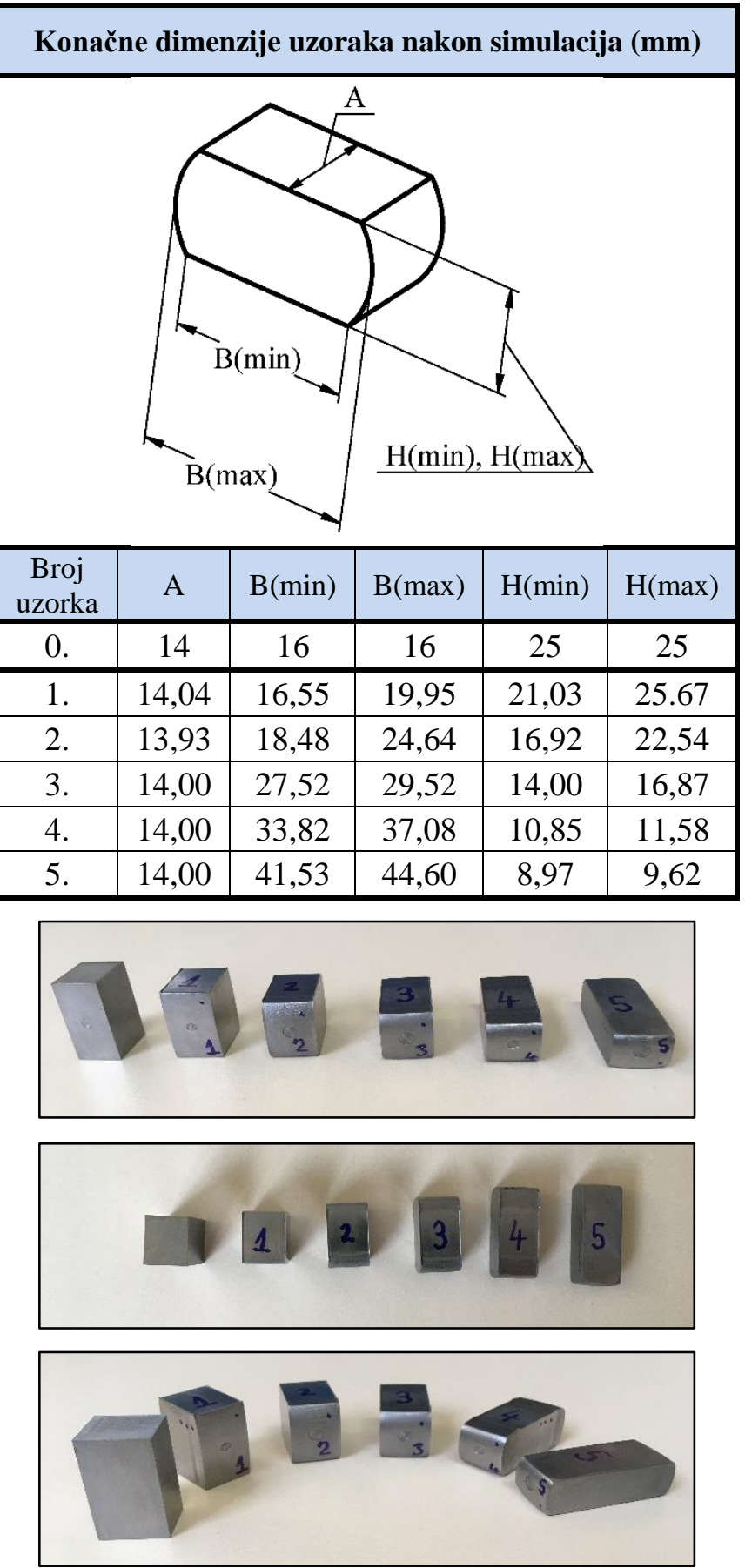

Slika 5.4. Uzorci nakon obrade ravanskim sabijanjem

Na slici 5.5 prikazan je dijagram [Sila - Hod] za uzorak koji je tokom procesa deformisanja bio izložen maksimalnoj zadatoj vrednosti hoda prese. Ovaj dijagram najbolje od svih preostalih dijagrama prikazuje promenu deformacione sile tokom procesa ravanskog sabijanja uzoraka. Kod svih pet uporednih dijagrama oblik obe krive se poklapa, ali sa odstupanjem vrednosti sile deformisanja. Vrednost sile deformisanja koja je dobijena simulacijama najviše odstupa pri manjim opterećenjima kod uzorka 1 gde je veća od realne sile dobijene eksperimentom $u$ proseku $83 \%$. Najmanje odstupanje javlja se pri najvećem opterećenju kod uzorka 5 gde su se dijagrami približno poklopili. 


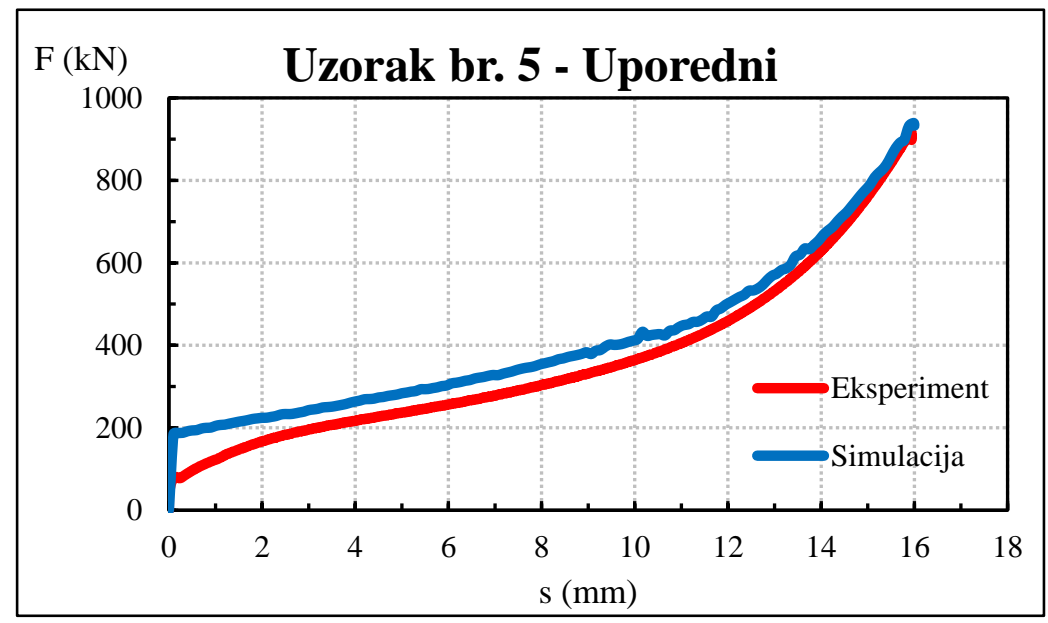

Slika 5.5. Uporedni dijagram [Sila - Hod] - Uzorak 5 (maksimalan hod)

\section{ZAKLJUČAK}

Povećanje mogućnosti istraživača, inženjera i tehnologa koji se bave izučavanjem TPD-a kroz sposobnost simuliranja procesa numeričkim metodama imalo je za posledicu poboljšavanje karakteristika proizvoda dobijenih TPD procesima tako što im je omogućilo da jasnije vide, razumeju i prate proces proizvodnje.

$\mathrm{Na}$ osnovu uporedne analize rezultata računarskih simulacija zasnovanih na numeričkim metodama i rezultata eksperimentalnih ispitivanja, došlo se do sledećeg zaključka:

Svaki od pet dijagrama [Sila - Hod] dobijen pomoću simulacija ima identičan oblik krive sa svojim suparnikom dobijenim pomoću eksperimentalnih ispitivanja. Pri malim opterećenjima, vrednosti sile deformisanja kod simulacija su veće od onih dobijenih pri eksperimentalnim ispitivanjima, ali se na većim vrednostima opterećenja usklađuju.

Računarske simulacije procesa hladnog deformisanja softverskog paketa SFTC DEFORM 11.0 daju zadovoljavajuće tačne rezultate prilikom rešavanja numeričkih simulacija problema hladnog deformisanja u uslovima ravanskog stanja deformacije sa sprečenim bočnim širenjem materijala pripremka i mogu se koristiti za prikupljanje informacija o ponašanju materijala prilikom procesa deformisanja gde se radni predmet deformiše u uslovima ravanske deformacije.

\section{LITERATURA}

[1] Plančak, M., Vilotić, D. Tehnologija Plastičnog Deformisanja (Metal Forming Technology). Novi Sad: Univerzitet u Novom Sadu - Fakultet tehničkih nauka, 2012.
[2] Plančak, M., Vilotić, D., Vujović, V. Tehnologija plastičnosti u mašinstvu II. Novi Sad: Univerzitet u Novom Sadu - Fakultet tehničkih nauka, 1992.

[3] Kuzović, M., Analiza Procesa Sabijanja u Uslovima Ravanske Deformacije sa Eksperimentalnom Proverom - Master Rad. Novi Sad: Univerzitet u Novom Sadu - Fakultet tehničkih nauka, 2021.

\section{Kratka biografija:}

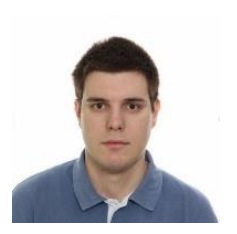

Milomir Kuzović rođen je u Užicu 1996. god. Master rad na Fakultetu tehničkih nauka iz oblasti Obrada metala deformisanjem odbranio je 2021.god.

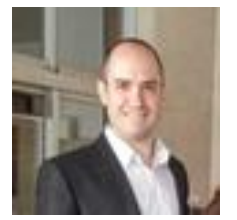

Marko Vilotić rođen je u Novom Sadu 1979. god. Diplomu osnovnih i magistarskih studija, kao i doktorat stekao je na Fakultetu tehničkih nauka. Na Fakultetu tehničkih nauka (Katedra za tehnologije oblikovanjem $\mathrm{i}$ inženjerstvo površina) radi kao docent.

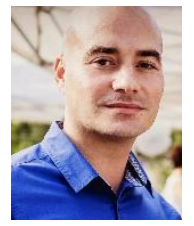

Jovan Dorić rođen je 1983. godine, doktorirao je na Fakultetu tehničkih nauka 2012. godine, trenutno radi u zvanju vanrednog profesora i vrši dužnost šefa katedre za motore i vozila. 